ISSN: $1782-2041$

DOI: $10.25518 / 1782-2041.1164$

\title{
The Freedom(s) within Collective Agency: Tuomela and Sartre
}

\author{
By BASIL VASSILICOS \\ Mary Immaculate College / University of Limerick
}

\begin{abstract}
In this paper, the goal is to investigate the nature of freedom enjoyed by participants in collective agency. Specifically, we aim to address the following questions: in what respects are participants in collective agency able to exercise freedom in some weaker or stronger sense? In what ways is such collective or common freedom distinct from the freedom ascribed to individuals? Might there be different sorts of freedoms involved in and tolerated by collective agency, each of which has its own role in determining the nature and efficacy of the bond uniting its participants? Clarification of just what such freedom may involve and how it subsists within collective agency is not only important for being able to demonstrate the instrumental value of social ontology to contemporary political debates. It may likewise contribute an important dimension to the descriptive psychology of collective agency and shared intentionality, which is an approach deserving of more attention. Here, such clarification is undertaken via a comparison to the notions of freedom at stake in the respective accounts of sociality and collective agency provided by Raimo Tuomela and Jean-Paul Sartre.
\end{abstract}

Some recent papers (Tollefsen 2014; León and Zahavi 2016) have taken issue with how contemporary researchers in social ontology seem to neglect "the experiential dimension" of human "capacity to share intentions" (ibid., 220). The lack of regard for the "experience-based aspects" (León and Zahavi) or "qualitative aspects" (Tollefsen) of this sharing threatens to call into question the depth and robustness, if not the very philosophical importance, of the 
models of sociality advanced by such research. Because prominent social theorists such as Bratman, Gilbert, and others tend to focus on the "propositional" or "normative" dimensions of sharing phenomena, they risk saying very little about what such forms of intentional sharing "actually [amount] to" (ibid.). The question, then, is whether explanations of experiential sharing can go further than statements, à la Searle, that collective intentions "involve 'a sense of us' and of 'doing something together'" (ibid.). León and Zahavi, for their part, see an opportunity for remedy of this oversight in exploring in detail the "resources" available within the phenomenological tradition concerned with social phenomena.

If the preceding may be correctly understood not only as a warrant for their own methodology but also as a call to be taken up, the goal in this paper will be to investigate this so-called experiential dimension of collective agency via one particular line of inquiry. Namely, we wish to explore whether this experiential dimension in collective agency might also include or involve a sort of freedom that may be enjoyed by participants in collective agency. We want to find out in what respects participants in collective agency may be able to experience a kind of freedom that is consonant with and made available by participation in collective agency. The phenomenon we aim to point at here is not simply the "disjunction condition", as thematised by Gilbert $(2009,172)$, which has to do with how, at any given moment, an individual ought to be able to distinguish between his or her own intentions, actions, and ends and those of the group (e.g. plural agent) of which they are part. That would only amount to a kind of freedom from the collective or apart from the collective. Rather, we mean to indicate a question having to do with the possibility of a sort of freedom within collective agency. Indeed, might there even be different sorts of freedoms involved in and tolerated by, or perhaps even requisite in, collective agency, each of which has its own role in determining the nature and efficacy of the bond uniting its participants? Our contention is that clarification of just what such freedom(s) may involve and how it may be experienced and structured within collective agency will not only be important for being able to demonstrate the instrumental value of social ontology to contemporary political debates. It may likewise contribute an important dimension to the descriptive psychology of collective agency and shared intentionality.

Even if it is granted such an account of freedom within collective agency might constitute an interesting desideratum, it cannot be taken out of hand that there are grounds for thinking that such a thing exists or ought to be accounted for. It should be noted that, barring a few notable exceptions (Hindriks 2007; Pettit 2001), such questions about freedom within collectives has garnered relatively little attention in contemporary discussions of social ontology, and has

\section{3}


seemed more of a matter for philosophers with an orientation towards political concerns (Kramer 2003; Cohen 1991). From a certain perspective, this is understandable. Given the varied and sometimes incompatible current theories as to what unites or is shared by collective agents, it seems natural that most attention would be given to how, within collectives, individuals are bound or united in agency, that is, how certain forms of 'unfreedom' (sometimes discussed as relational or normative constraints within collective agency) characterise and condition collective agency. All the same, this is not to say that no one has ever come close to considering such a problem. To a great extent, one cannot put forward an account of what binds or constrains collective agency without at the same indicating, even if only in a backhanded fashion, what allows them to some degrees of unboundedness. However, in those few cases where questions of freedom have been explicitly broached within social ontology, this seems largely to have been done from the perspective of whether collective freedom could be reducible (or not) to individual freedoms. For instance, Hindriks (2007) argues contra Cohen that maximal individual freedom cannot be either a necessary or sufficient condition of what he describes as corporate freedom (i.e. for the freedom of a group/ collective agent), and that corporate freedom can likewise be independent of individual freedoms. While Hindriks does this by examining some useful thought experiments in social ontology, he does not shed much light on what it might like for any group members to experience such corporate freedom, nor on what sorts of participatory and agentive intentions that experience might involve.

Hence, given this apparent lack of attention, what might be some reasons for thinking that there could be such kind of freedom within collective agency? What could be the basis of the suspicion - ours, at least - that its omission from discussions of the nature of collective agency is not without certain risks? One kind of basis for this question can be found if we consider some recent work by Butterfill, in which he puts forward an account of the type of planning and coordination ("parallel planning") that in his view best characterises "alpha" (true, paradigmatic) collective agency (Butterfill 2015). Even while depicting his aim as primarily being about capturing the features of such "alpha" collective agency $(152,165)$, Butterfill nonetheless seems open or at least neutral with regard to the claim that not all phenomena of collective agency may be created equally. There may be in other words "degrees" of collective agency, and one ought not rule out a pluralism of collective agency, even if accounting for such is not one's explicit aim (as in Butterfill's case). In the context of his argument, by "degrees of collective agency" what Butterfill seems to have in mind are different tolerances for either coercion (by 
one agent of another) or fortuitousness to factor into, and not be the nullification of, collective agency (152). Here, however, we may append a query whether there may be other compelling manners of understanding such "degrees of collective agency". With respect to the role of planning in collective agency, for instance (Butterfill's topic in that article), we may well wonder whether not all forms of collective agency permit of exactly the same forms of flexibility and do not rely upon the same degrees of coordination or planning. If that is plausible, then on our view there might be some variance of unplannedness within the coordination and cooperation that characterises collective agency, for instance under the guise of flexibility or creativity, available to collective agents. Moreover, even if we are entitled to extrapolate from this observation and derive from it a notion of freedom within collective agency, one may still wonder whether any and all sorts of freedom enjoyed by participants in collective agency stops there. For instance, is the freedom within collective agency determined chiefly with respect to the goal or object of that agency (how ambiguous or clearly defined it is, how simple or complex it is), or might participants avail of another sense of freedom still, apart from how uncoordinated or creative their shared action turns out to be?

We can put more of a point on these questions and their motivation with the aid of an example. For instance, on a grey, rainy morning, a commuter takes an abrupt, painful-looking tumble down some slippery cement stairs. A group of other commuters interrupt their journeys and gather around this person and try to help him. One person gathers the things that the fallen person has dropped; another makes sure he doesn't move, lest he might have injured his neck or spin. One woman phones for an ambulance, while a fourth goes to see if the station might offer a first aid kit. What is going on in this type of situation, where we have a group of people gathering to help a fallen commuter? In the first place, it does seem like there is a plausible case here of collective agency; this is insofar our good Samaritans are not being coerced into helping, and seem to share the same goal, namely, of helping the fallen person. Moreover, they seem to be working and coordinating together in order to reach that goal ${ }^{1}$. Yet we might wonder about what other features might be

\footnotetext{
${ }^{1}$ Further caveats may be raised here on whether our example satisfies a well-defined and effective constraint condition such as to constitute an instance of collective agency. These may include the fact that in our examples such participants lack common knowledge of each other, may not check plans with each other and that the set of participating agents is not fixed beforehand. On our view, such concerns would restrict the domain of phenomena of collective agency implausibly, because the boundaries would be too narrow. On such caveats and constraint conditions for phenomena of collective agency, cf. Paternotte 2014, 107.
} 
attributed to how they are going about reaching that goal. Insofar as they form a group of people helping someone, does each of them primarily feel somehow constrained in their actions by this group? And if that is the case - as might seem likely to some - does that then exhaust what each person is able to feel as the 'we-feeling' one might have in the group, namely, a sharing of a goal or plan which constrains each individual?

In the ensuing, the attempt will be to explore these questions via a comparison to the notions of freedom at stake in the respective accounts of collective agency provided by Raimo Tuomela and Jean-Paul Sartre. There are a couple reasons for thinking that juxtaposing these two authors and their approaches to these questions might be fruitful. The first has to do with the methodologies and the conceptual resources each may bring to bear on this problem. Tuomela may be thought to be highly representative of and also highly represented within how contemporary social ontology tackles such issues; Sartre's approach on the other hand would appear highly idiosyncratic (if not incomprehensible) to many a reader today and seems not to attract too much attention in the literature. This gulf between them already suggests one issue of interest; is the superiority of the one's approach over the other to be taken out of hand, especially when the latter, Sartre, would seem much more aligned with the interest in the 'experiential aspects' of collective phenomena mentioned earlier? The second reason for linking the two, tied to the first, has to do with the radically different sorts of answer each arrives at, concerning the questions whether and how there might be something like freedom (for participants) within collective agency. Could then each of our interlocutors have something to say to the other, which might open up a new perspective on our problem? Can their differences, in other words, be stimulating for considering which of the two might be closer to the truth, in what ways, and why?

Turning first then to Tuomela, part of the appeal of his account is that he provides a many-levelled analysis of the types of cohesiveness evinced in collective agency according participants' intentions or commitments. These are accounted for in terms of his notion of different configurations of 'I-mode' and 'we-mode' "we-intentions" and in terms of a distinction between "operative" and "non-operative" members of collective agency, each of whom has different levels of cognition about and authority over a group's collective agency (Tuomela 2007, 2013). On the basis of understanding how Tuomela deploys these notions in order to explain collective agency, it can be argued that there remains in his account, despite its sophistication, a basic tension between freedom and collective agency. For the participants within collective agency, freedom can only exist and be tolerated within collective agency when the latter takes on less coordinated and thus less cohesive forms. On the other 
hand, for Tuomela, the more the goals or the conditions of collective agency call for greater cooperation and cohesiveness, the more such freedoms form a threat to that very collective agency. This juxtaposition between group cohesiveness and freedom suggests that to cash out this finding in Tuomela, two steps will thus be needed. The one is to develop a picture of how Tuomela accounts for how group agency comes about (as a kind of cohesiveness), and the second is to clarify what sort of role for and meaning of freedom is accorded therein. Basically, what these two steps will amount to is a set of claims about how collective agency, when it is truer or more "ideal" collective agency according to Tuomela's terms, has to debar or at least strongly constrain an individual's freedom.

For Tuomela, as for some others working on social ontology, there are basically two factors determining whether collective agency between individuals can come about. The first is quite fundamental but still quite broad, and can be linked with what is sometimes discussed as the phenomenon of 'collective acceptance' or collective belief. For there to be anything like collective agency, there needs to be shared group reason(s) - a kind of (shared) ethos in which goals, values, beliefs, and norms are shared across a number of individuals ${ }^{1}$. Of course, simply holding certain beliefs, even shared ones, does not necessarily lead to action, and this is where a second factor comes into play; in order for collective agency to come about, there has to be an intention to act which is shared or which is intended in common by some number of individuals. These last are what Tuomela calls 'we-intentions', by which he means intentions people have to do things which they could only do together with other people (hold a debate, play a soccer match) or which they explicitly wish or aim to do together (build a boat, clean up a park). These we-intentions are thus defined by targeting shared goals that people may act towards; by contrast, so-called 'I-intentions' are characterised by individual or non-shared goals.

One of Tuomela's key contributions to social ontology comes at this point in the story. Apart from being careful to distinguish between non-shared (or non-cooperative) and shared intentions (termed 'I-intentions' and 'we-intentions' respectively), Tuomela is careful to point out that these shared or weintentions that condition collective agency can have different modes, in function of just the manner in which a person is committed to reaching or acting towards that shared goal. On the one hand, a we-intention can have an 'Imode', in which an individual functions merely as a private person, privately committed to a (shared) goal. Thus, as a good Belgian, I can be individually,

${ }^{1}$ Cf. Tuomela 2007, 22-23. 
i.e. privately committed to the shared goal (with a multitude of other Belgians) that every Belgian beer be poured in its proper glass. This means, for instance, that I act in some way towards that goal. I try to enlarge my glass collection at home as much as I can; when I have a beer poured for myself or others, I check or request that this 'rule' is being followed. However, Tuomela (2007) argues there seem to be no or few intersubjective or epistemic requirements involved in the effectuation of this we-intention within the I-mode, and this seems plausible; for instance, in being committed to composting as much of our household waste as possible (a shared goal), I don't necessarily have to look to, or coordinate with, or even communicate with others as I act towards that goal.

On the other side of this distinction, we have the way that we- or shared intentions permit of a 'we-mode', and in such cases, argues Tuomela, we can see certain more robust or cohesive forms of collective agency occurring. These last instances are not a mere aggregate of private commitments to a shared goal (as was the case in the former), but appear to involve the following features for the we-intention supposedly at work in them: $1^{\circ}$ There are certain cases of collective agency where, for the individuals holding a certain shared goal, each intends to act towards that goal as part of a group acting towards that goal. In Tuomela's terms, this means 'the group [qua group members] intends to do $\mathrm{X}$ as a group'. $2^{\circ}$ This in turn means that in those cases (of the we-mode we-intention) each individual has to be turned towards others with whom they share a certain goal, if the individual is to act towards that goal with them as part of a group ${ }^{1}$.

How to account for this difference between these cases of the I-mode and the we-mode? What distinguishes I-mode from we-mode we-intentions? What in other words is going on at level of one's intentionality when one would 'look to' or 'coordinate or communicate with' others in the we-mode we-intention? To put more of a point on the matter, behind such a terminology on Tuomela's part, we can clearly discern an agenda to differentiate between those sorts of collective agency that have more 'bond' or glue within in them, and those that have less. So how to account for these greater and lesser quantities of such glue? Echoing a vocabulary made popular by e.g. Gilbert,

\footnotetext{
${ }^{1}$ The we-mode means that when I intend, "that also others (or a sufficient number of them) [have to] participate", this is both a "conceptual and rationality condition for one's intention to participate" (Tuomela 2007, 93). I.e: "The joint action opportunities conditions" include "also that the others will participate [...]" (ibid.). Tuomela does not seem to distinguish closely between 'joint action' and 'collective action' (cf. 2007, 123) nor between collective agency and joint agency, as others such as Butterfill might (cf. 2015). Whether he is justified in not doing so lies beyond our current scope.
} 
Tuomela's answer is that this depends, at the level of the constitution of weintentions, on the kinds of commitments members of collective agency hold. These are namely collective commitments and social commitments, and in wemode we-intentions they both emerge in a significant manner and appear to evince a special relationship. A key explanation of their relationship is the following:

The social glue and cohesion provided by collective commitment should be present and required in these contexts. Part of what is involved here - over and above what aggregated private commitments give - is the social commitment involved in collective commitment: being committed to each other, the group members can better rely on the others to perform their respective tasks, which, especially in the case of interdependent and joint actions, is central. Social commitment to others and to the group is the core of the reproachability feature involved in collective commitment: a publicly we-committed member who leaves the joint project or intentionally violates the ethos can be criticised by the others, whereas if he had been committed only 'to himself' he would in general have been less criticisable socially for letting the others down (Tuomela 2007, 37).

Collective commitment may be thought of a commitment not only to a shared goal but also to a shared action, namely, 'I commit with you to achieve $x$

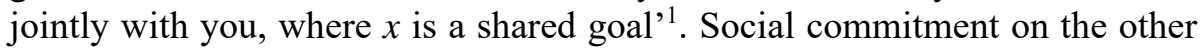
hand, involves a kind of commitment to the others with whom one would share an action, i.e. it is 'commitment to one another to participate to realise $x$ '. What is important about their relationship according to Tuomela is that collective commitment must entail social commitment. In other words, one cannot be committed with another to shared action without at the same time being committed to that other (to share action, 'to participate to realise $\mathrm{x}$ ').

'Collective commitment involves social commitment', 'committed with, committed to'...; what is going on here? In essence, Tuomela derives commitment to one another from the commitment with one another, and makes both essential to what he considers to be true, robust, or "ideal" collective

\footnotetext{
${ }^{1}$ Without explicitly stating as much, Tuomela seems to hint at one point that collective commitments seem to involve something like a promise $(2007,36)$. There is at least a question here for Tuomela on how much or how necessary speech acts or social acts may be involved in collective commitments. It should also be noted that collective commitments can be shown in different ways and to different degrees; again, in Tuomela's terminology, a non-operative group member (a non-decider) can show collective commitment in a weak sense despite failing tacitly to accept the group intention, namely through the mere fact of their functioning within the group $(2007,96)$.
} 
agency. His reasoning on this point runs as follows: from collective commitment there devolves to each participant a set of reasons to act, constituting their respective roles, tasks, and 'parts to be done' within the shared goal, and such members have to be able to rely on the others, "especially in the case of interdependent and joint actions" $(2007,37)$. This creates a situation where enforceability and "reproachability" for such roles and tasks (or failing them) is a key presumption of the collective commitment ${ }^{1}$. On Tuomela's view, each person cannot truly and faithfully commit to realise something together ('with one another'), unless each person can rely on others and hold them accountable for their roles ('to one another'). In other words, for one individual to commit with another...there have to be "social oughts and mays" in place to which those individuals are also committed; these are namely rights and duties which gives individuals reasons to act in a group, as a group member ${ }^{2}$. This notion of collective commitment "involving" or containing social commitment thus forms the backdrop on which Tuomela develops his notion of "group-social normativity," which he distinguishes from 'normativity proper,' e.g. "moral, legal, prudential (etc.) normativity" $(2007,27){ }^{3}$

However, an important question remains here; one might well still wonder about the grounds on which such rights and duties could be generated, let alone enforced or reproached. On the basis of what sort of 'glue' or bond could

\footnotetext{
${ }^{1}$ It is both a "conceptual" and "rational" presumption according to Tuomela; the agent cannot understand their commitment without this reproachability, nor could the collective commitment be expressed or intended in the first place without it (Tuomela 2007, 104).

2 "Social commitments assumed to be entailed by collective commitments" are a kind of "social normativity," having the form of "social 'oughts' and "mays"" (Tuomela 2007, 27).

${ }^{3}$ Cf. Tuomela 2013, 252. In our view, the status and the significance of normativity in Tuomela's account remains a fraught question. On the one hand, given the explicit distinction he makes between "proper normativity" and "group-social normativity", the literature tends to classify Tuomela as a "non-normativist" on collective intentionality (Gomez-Lavine and Rachar, 2019, 98; Schmid, 2009, 42). On the other, it is difficult to conceive of what Tuomela could mean by such "group-social normativity" and by the idea of "social oughts and mays" if these notions are not based to a large extent on some version of 'normativity proper'. For instance, it seems Tuomela would invite a host of problems if "group-social normativity" were to be framed as a type of epistemic or semantic normativity. In an important note, Tuomela (2007, 260, note 53) even seems to go so far as to concede this, stating that his notions of social and collective commitments exhibit a "functional" resemblance to the role they play in a normative account à la Gilbert.
} 
other participants in the collective action be reproached when failing to conform to these rights and duties (especially given that we cannot call upon any external moral framework in order to account for them)? Such grounds cannot come from or be met by the 'group ethos', the first condition of collective agency according to Tuomela, for (among other reasons) as we have seen such ethos can be shared 'privately', i.e. within the I-mode ${ }^{1}$. The answer for Tuomela has to do with how, in collective agency, we have to be as much committed to each other as to our shared action and our shared goal: "being committed to others [e.g. the social commitment, B.V.], we can better rely on others to perform their respective tasks... Social commitment to others and to the group is the core of the reproachability feature involved in collective commitment" (ibid., 37). In other words, in true collective agency, each person and their actions has to be open to scrutiny by others.

A useful perspective for understanding this point about how collective agency involves different kinds of commitments is offered if one reflects on how such agency seems to have a kind of transparency (with and to others) as a requirement (ibid., 38). As in our example from the train station, when people are acting together towards a shared goal, not everyone can be doing everything at once, and it makes sense for each person to be aware of what the others are doing, in order for each person and the shared action to be effective. The sort of transparency we are referring to here may then be thought of a kind of monitoring which follows from what Tuomela frames as the "collectivity condition" of collective agency, namely, that all participants in the collective agency must be equally satisfied with the status of fulfilment of the shared goal of that agency ${ }^{2}$. This monitoring reflects quite a high cognitive loading on the part of all the participants in the collective agency, because each person has to be aware of what the others are doing in function of their roles and also of the extent to which each other participant's actions are adequate to reaching the shared goal. It is also cognitively demanding from a dynamic perspective; it must both evolve and go back and forth between participants, as they mutually ensure that the others with whom they are intending and acting are indeed 'doing their parts' as each individual does their own part, and as those 'parts' themselves evolve in function of the shared goal. However, Tuomela is careful to warn us, this transparency is conceptually and normatively demanded by the

\footnotetext{
${ }^{1}$ Another consideration here is whether the 'group ethos' includes concrete shared goals that could constitute the objective(s) of the forms of collective agency Tuomela aims to explain.

${ }^{2}$ Cf. Tuomela 2013, 40ff.
} 
participants' having of the intention to act collectively, but is not always necessarily acted upon. It thus allows for different strengths or levels of reciprocity - namely where this monitoring of the commitment is or is not accomplished to some greater or lesser extent. That is, this monitoring is only obliged, but not presupposed to be enforced. Nonetheless, there always remains, and has to remain, an opportunity for participants involved in the collective agency to hold each other accountable for their roles and parts, duties and rights, since the collective commitment (especially because its inclusion of social commitment) gives all group members "joint authority" and makes them accountable to each other.

What does all this "actually amount to" in terms of collective agency from an experiential or qualitative perspective (if we think back to León and Zahavi's question from earlier)? What does it lead to in terms of a perspective on (shared) freedom? An attractive feature of Tuomela's account is the way in which it offers a rich taxonomy of and philosophical underpinning for many different forms of collective agency, according to a number of different combinations and strengths of we-mode and I-mode we-intentions, among other variables that he introduces. For instance, for persons involved in organising social-communal initiatives (such as the many 'climate-neutral endeavours' going on right now in many urban and rural communities around the world), such organisers may witness and may also want to encourage through their efforts a multitude of forms of participation in the collective action, i.e their initiative. These may range from more token forms of participation (wearing a badge, signing up for a newsletter) to more creative and demanding ones, all of which community organisers and campaigners today sometimes classify according to a 'ladder of participation'. . In this respect, Tuomela can be seen to offer an elegant and detailed explanation of the internal differences between these forms of participation, and of what might be required in one form but not another. On the other hand, we cannot be blind to the fact that Tuomela does not remain value-neutral in his explanations. Certain types of collective agency are more truly 'collective' than others, insofar as, in his view, only the wemode we-intention achieves what he considers as a 'strong we' or as "ideal" collective agency (Tuomela 2013). This 'strong we' occurs namely in instances where social expectations and pressures with a normative force within collective agency are not only generated but also enforced (via transparent, reciprocal monitoring), thereby bringing about a lived notion of 'togetherness', of "standing or falling together," of being "in the same boat". Because, accord-

${ }^{1}$ Cf. Arnstein 1969. 
ing to Tuomela $(2007,282)$, "mere reciprocity is not sufficient to generate sustained cooperation", such cooperation requires "strong reciprocity"; where the latter is especially in his understanding not only "a predisposition to cooperate with others" but especially a predisposition "to punish (at personal cost, if necessary) those who violate the norms of cooperation" $(2007,150)$. "Strong reciprocity" thereby requires "altruistic punishers", that is, individuals highly engaged in and committed to enforcing the collective and social commitments (ibid.).

At the same time, however, this 'strong we' seems to come at a cost, and there can be no mistaking it; its name is freedom or autonomy that participants may have or experience. That is to say, freedom within collective agency can only exist as a kind of trade-off or at best a kind of indeterminacy or leftover, the more the mechanisms of collective commitments are enforced, that is, the stronger the we is (qua we-mode we-intention) in collective agency. How might that trade-off be understood? To be clear, it should be remarked that Tuomela does not seem openly opposed to any form of freedom in his account of collective agency. This means that freedom must be accorded a special place in his account and that from the outset he envisions its relationship to collective agency as quite complex. This can be seen in the way freedom for Tuomela is both a condition and something given up in collective agency. On the one hand, freedom appears to be a necessary condition because, according to Tuomela, a defining feature of collective agency in its most basic form is that individuals enter into and participate in the collective agency willingly $(2013,15)$. Tuomela's basis for this claim is methodological and formalistic; insofar as the explanandum of his account is collective, i.e. shared, agency from the perspective of necessary and sufficient intentions that individuals have and act upon, that account must as a rule exclude any social phenomena by which persons would be brought to act in line with each other by external, situational factors, such as duress, force, or what he calls "external coercion". At the same time however, he also suggests that any person entering into and participating in collective agency must be amenable to, if not equally open to participate in, what he calls 'internal coercion'. self a rather wide berth on what this does not mean. Namely, he remarks, holding a gun to someone's head would not fall under it $(2007,15)$. Nonetheless,

\footnotetext{
${ }^{1}$ Cf. Tuomela 2013, 17: "A paradigmatic we-mode group is democratic and autonomous (free from external domination), able to decide about its internal affairs (e.g. its ethos and other goals and views). This is compatible with such a group still being internally unfree concerning its member freedom (e.g. some members may try to use power to coerce others and in other ways to prevent their freedom of action)".
} 
the clear implication is that a participant in collective agency must surrender their autonomy, which he terms their 'metaphysical freedom', in order to form part of the 'strong we.' This requirement goes hand in hand with what we discussed as the social commitment 'within' or entailed by collective commitment above; as we saw, the chief manner in which Tuomela proposes to understand how an individual might be committed to others is vis-à-vis a surrender of one's freedom. Such a surrender makes possible the reproaching and enforcing reciprocity that bonds or glues members of collective agency by ensuring that all the members of the collective agency are doing their parts, falling in line or meshing like so many cogs and gears. Yet what happens to one's own sense of freedom, for instance with respect to the how one might deliberate about and act upon one's own role and obligations in function of a shared goal with others? Tuomela $(2013,17)$ answers as follows:

A paradigmatic we-mode group is democratic and autonomous (free from external domination), able to decide about its internal affairs (e.g., its ethos and other goals and views). This is compatible with such a group still being internally unfree concerning its member freedom (e.g., some members may try to use power to coerce others and in other ways to prevent their freedom of action).

That is, any such freedom becomes a mere "desideratum" $(2013,171)$, a perhaps felicitous nice-to-have, which is surplus if not extrinsic to the requirements of collective agency ${ }^{1}$.

There would be further ways to explore more the repercussions of Tuomela's account ${ }^{2}$, and we should not fail to notice that a further sort of commitment has crept into his account of collective agency, namely a sort of 'unfreedom' commitment ${ }^{3}$. With this finding in hand, though, we want to turn to

\footnotetext{
${ }^{1}$ Cf. Tuomela 2013, 170: “[The] giving up part of one's de facto authority is typical and indeed necessary for much of social life. A requirement of autonomy in an ontological sense (that is, free from contextual empirical constraints) or in a moral sense can still be retained, but rather as a desideratum than a right that others are obligated to respect in all situations."

${ }^{2}$ For instance, in terms of how Tuomela describes the 'we-feeling' or in terms of how he understands the charity or altruism of the 'altruistic punishers' upholding the social commitment.

${ }^{3}$ For a helpful discussion of the role of normativity or enforceability in Tuomela's account of collective intentionality and collective agency, cf. Schweikard 2017. Our discussion differs from Schweikard's in that he is interested in the conflicts of obligation that may arise, for instance, between a person having individual and group-reasons
}

\section{4}

Bull. anal. phén. XVI 2 (2020)

https://popups.uliege.be/1782-2041/ @ 2020 ULiège BAP 
a Sartrean account that seems in many ways diametrically opposed to that of Tuomela's. One key way in which this is apparent is the manner in which Sartre insists on how a sense of freedom is not a matter of a trade-off or something left over, once other conditions of collective agency are fulfilled; rather, Sartre insists, a form of freedom constitutes the core feature of collective agency. This emphasis surfaces time and again in his discussion of the group-in-fusion and its path to common or collective action ${ }^{1}$. Given such claims on Sartre's part, there is a question here. What should we make of this different approach by Sartre? Does anything back it up? Indeed, one objection that might be raised at this point is that there is a kind of philosophical ruse in even asking about freedom within collective agency in the first place. This objection might runs as follows; collective agency, as we have already seen, seems to exclude any forms of human behaviour involving involuntary compulsion. That distinction is one of the ways by which we know what we are concerned with; it is one of the basic criteria for identifying collective agency in the first place. In other words, collective agency by definition always has to involve a 'willing' on the part of its participants, under some form or other to be specified ('doing one's part,' etc.). Insofar, then, as this willing is necessary to any collective agency, there is not only no tension between collective agency and freedom, but also no problem of freedom 'within' it. Freedom conditions and thus is a part of collective agency ex hypothesi.

There are different responses available to this 'conditions of participation' objection, consideration of which can shed some light on Sartre's approach. One response concerns whether such willing on the part of individuals to participate in collective agency should be understood (strictly or partly) as a willing to give up one's freedom; might it not be understood as a change in or development of one's freedom? A second, more pointed response is that even if such an objection were true, it still would miss the mark; it would not tell us anything about whether there is such a thing as freedom within collective agency or about what it would look like. This is because, whatever the case may be, the objection only concerns (the conditions of) an individual's openness and desire to participate in collective agency, but not the realisation or embodiment of that participation in a shared intention to act together with

to act, and whether and how well Tuomela might be able to accommodate such conflicts.

${ }^{1}$ Cf. Sartre 2004, 401: "But the essential characteristic of the fused group is the sudden resurrection of freedom"; "[ [...] in the group-in-fusion, the leader is always me, there are no others, I am sovereign and I discover in my own praxis the orders which come from the other thirds" (ibid., 396). Cf. ibid., 402-406. 
others. In other words, the only thing this objection shows is that an individual's (free) willingness to participate ought not be confused with what that individual will share and participate in through collective agency.

In our view, such responses go some ways towards pointing at what Sartre is after, and provide a motivation for investigating his account further, but there is no getting around the fact that his position on the freedom within collective agency remains poorly understood, perhaps because it is hard to understand in the first place. Is his notion of such freedom merely a historical curiosity, or perhaps some sort of a conceptual chimera? Is it maybe the conceptual manifestation of a certain political agenda on Sartre's part coming out in his attempt to offer an account of sociality that goes beyond some of the gaps of his earlier philosophy? Or is there something to it, something that can still speak to and indeed inform contemporary social ontology debates? In the ensuing, we aim to outline some of the main arguments behind Sartre taking such a position, and perhaps even point to some questions they might raise for Tuomela's account. There are two areas in particular that are worth looking at; on the one hand, the relations one participant has to other participants in collective agency, and on the other, the awareness of efficacy or action that accompanies collective agency. In both of these areas, Sartre may be seen to find some interesting considerations for thinking why there may be freedom within collective agency.

In the Critique of Dialectical Reason, the chief but not sole work by Sartre dealing with such issues, we can find a substantial portion of his remarks on the role of freedom in collective freedom in the section in which he deals with the emergence of group phenomena in everyday life, which he terms 'groups-in-fusion'. In aiming at a non-circular description of such phenomena, he nominates certain conditions for the emergence of collective agency. Namely, there needs to be the following ${ }^{1}: 1^{\circ}$ common needs, something individuals can address together; $2^{\circ}$ common objectives, something individuals can reach together; $3^{\circ}$ common praxis, something individuals can do together.

Much could be said about this structure and about how these conditions relate to each other; for our current purposes, it suffices to note that, through an analysis of such conditions, Sartre is interested in a notion of groups that is more inclusive and internally differentiated than one that would, for instance, split groups into two basic classes of "teams, committees, clubs, and courts" and of "racial groups, gender groups, ethnic groups [...]"2. Moreover, we wish to highlight the significance of the requirement, 'common', in each of these

\footnotetext{
${ }^{1}$ Sartre 2004, 350, 446.

${ }^{2}$ This is a classification proposed by Ritchie $(2015,314)$.
} 
conditions. It signifies not just a dependence on others but also a way of being or interacting with others, akin to the 'glue' or 'bond' previously mentioned vis-à-vis Tuomela. However, there is a question for Sartre regarding just how to frame this commonness, which is to say, this way of being together and interacting with others with respective to needs, objectives, and actions. Sartre states in fairly clear terms that he does not think it ought to be understood in terms of either solidarity or cooperation $(2004,395)$, for that would be to presuppose the very thing he aims to explain. Nor is it any kind of "metaphysical reality" (ibid., 404), "inert statute of unity" (ibid., 391), or "single quality" of each participant's act(s) within collective agency ${ }^{1}$. Sartre is then correspondingly agnostic about whether "closeness', as a sort of "gelatinous glue" or bond between participants (ibid., 395), is the right paradigm for grasping their 'commonness' of need, objective, and action, and perhaps more importantly, for grasping the character and presence of these others with and to whom Tuomela thinks we commit in collective agency. For instance, in crowded cities, in busy busses and trains, we may seem close, all too close to others. As has been shown by e.g. Goffman (1956, $66 \mathrm{ff}$.), we may even be seen, on account of such (spatial) proximity, to coordinate with others constantly and in very precise and definite ways, such as the manner in which we manage our body space and body orientation in relation to them, and in the way each communicates their intentions to others around them ${ }^{2}$. There is in such an observation the basis for voicing a Sartrean sort of question to Tuomela; such coordination together with others seems to have traits similar to the social commitment and its enforcement (namely a commitment to the other to realise the goal, apparently shared by each of us, of having as comfortable a commute as possible) ${ }^{3}$.

\footnotetext{
${ }^{1}$ On the 'distributivism' or the individualism of Sartre's approach to groups, cf. Caws 2014, 220-222.

2 Goffman's term for this is "body gloss" $(1971,128)$.

${ }^{3}$ One may of course dispute whether our example of the commuters exhibits anything resembling a shared goal, and Tuomela if not others certainly would. In defence of our interpretation we would point to the facets of such behaviours that show how commuters do not merely treat each other as turnstiles, poles or doors, etc., to be navigated in the pursuit of each person's own individual ends. Thus, in certain contexts commuters may signal each other of their intentions in both subtle and explicit manners (packing up one's belongings, direct a glance at a door), and anticipate and accommodate the intentions of other commuters (shifting one's bag or one's feet, move out of each other's way). It seems reductive to assume that both the purpose of such behaviours and the manner of their execution could be explained simply by how each individual is steering others around them in function of their own private (i.e. non-shared) goals.
} 
All the same, such behaviours evince, as our daily commutes show, very little 'true' or ideal commonness or togetherness ${ }^{1}$.

Sartre's thinking runs in a rather different direction, and may even seem idealistic. Distilled to its essential feature, his argument is that in the most basic and paradigmatic cases of collective agency, which he calls the "common action" conditioned by the factors outlined above, there are no others, or that others disappear. The commonness Sartre aims to describe is in other words one in which each participant does not care about others at all and has little regard for them. Instead, what each participant in the common action is most concerned with is the thing, i.e. the cause, risk, danger, emergency, or event at hand. In line with the methodological solipsism which seems to be de rigueur in contemporary social ontology, this caring and acting is very much an individual experience on the part of each participant - as if in collective agency, for the first time, one can truly care about something, and not only care, but actually do something about it as well. Sartre's position - about the kind of others with whom we interact in collective agency, and about the manner in which we do so - shows a kind of scepticism on his part about the importance and the role of sharing, if not also empathy, in collective agency ${ }^{2}$, and is consonant with his earlier attempts to elaborate human intersubjectivity not on the basis of any Husserlian or Schelerian models. Yet what then could the togetherness of collective agency be about, if not some fundamental sort of sharing? He will argue that there is another option, little explored in the history of philosophy. The key for understanding collective agency is not some way in which others appear in, are related to (e.g. via intentions), or are interacted with in a special way. It rather lies in the way that others recede or disappear in function of collective agency; that is to say, the way in which they become thirds.

Thirds are, in the first place, others of one's others; the term 'third' or 'third party' is a way of denoting how certain people remain outside or beyond our sphere of interactions, in either temporary or permanent fashion ${ }^{3}$. An individual does not see or know thirds; they remain 'submerged' in each person's situation (Sartre 2004, 366). The invisibility of thirds stems from their status as the underlying 'origo' from whom and to whom practical possibilities for action in any given individual's situation refer. In other words, thirds may be

${ }^{1}$ Cf. Sartre 2004, 350 on how having a "common object" does very little to unite individuals.

${ }^{2}$ For instance, insofar as every form of empathy must involve a self-other relation. On this point, cf. Zahavi 2014, 138.

${ }^{3}$ On the invisibility of thirds, cf. Sartre 2004, 366. 
thought of as predetermining the scope and limits of one's (practical) intentions in any situation that one might arrive in, like so many arrows painted on the tarmac of a road, lines hewn into hedges and paved into sidewalks, desire paths cut across swards of grass, and so on. Thirds 'always already' steer an individual's intentions by antecedently assigning meaning to the states of affairs by virtue of which each individual can express an intention to act in the first place. They thus remain by definition at one step removed from any such intention on an individual's part. A key feature of 'thirds' or 'third parties' in this respect is that they are to be sharply distinguished from the 'Others' with whom an individual can have commerce during daily life. Unlike those omnipresent 'Other' individuals with whom one interacts and with whom each individual is in competition for a scarcity of ends, spaces, and resources (if not autonomy), thirds cannot be seen and cannot be visualised or imagined. On Sartre's view, there can only be paintings or sculptures of, for instance, masses or crowds of individuals, but never of individuals related to each other as thirds (ibid., 374).

In common action or collective agency, Sartre's idea is that something particular happens to how an individuals relates to 'Others' and to 'Thirds'. Namely, in contrast to Tuomela's account which insists that others become more present or more prominent in collective agency, Sartre's idea is that certain others around one cease being mere or everyday, typical 'Others' when some individuals come to truly act together or in common. Instead, for a participant in the common action, such 'Others' appear under a different form, as a kind of 'explicit' third; that is to say, as a third with whom one experiences a connection via a common 'origo' of a practical possibility for action within one's situation. What Sartre will highlight as support for this claim is a contrast between how one is typically aware of one's actions in seriality and how a sense of action may be given to persons in the group-in-fusion. Namely, in the latter, Sartre stresses the way that, in the common action of the group-in-fusion, there is a kind of indistinguishability between actions that are 'one's own' and actions carried out by others persons around one. In the group-in-fusion, actions can be seemed to belong to one even if they do not originate from one, inasmuch as they stem from the group to which one belongs. It is as if both the scope of each practical intention as well as the range of possible practical intentions had been greatly widened, beyond any individual's non-shared, private hic et nunc ${ }^{1}$.

${ }^{1}$ Cf. Sartre 2004, 397 (emphasis added): "Thus, in contrast to the rout as seriality, this flight — which already projects itself obscurely as a means of regroupment - has everyone as its sovereign agent here in so far as it is common; and everyone produces 
We can think of this point, and consider its plausibility, once more in terms of our example from the train station. There has been a break for all of us, in our daily paths. We have to stop getting in the way of each other: that is to say, stop appearing to each other as 'Others'. There would have been no occasion for us to come together without this person's having fallen, but somehow also all of us chose to stop, to help, to be concerned. On a Sartrean reading of this situation (e.g. there are no 'Others' in collective agency), there is no 'Ithou' relationship at this moment of coming together to help this person. The concern - my concern, and our concern - is this person's having fallen, and it does not matter whose phone we use, who goes into the station, who picks up the person's things, etc. In the specific form of interaction or reciprocity which occurs at that moment of helping the fallen person, it does not matter to whom each action belongs, or where it originates from; why not? - Because at this moment, 'others' have receded. That is, my practical possibilities and intentions become entangled with theirs, as theirs become mine, in a way that could never occur as long as they are my 'Others' with whom I must divide the world. The Sartrean basis for such an analysis draws in particular on the phenomenology of each person's practical intentions in the common action; the individuals interrupting their commute for instance find themselves able to help the fallen person in a person in a novel way, one that each individual could not discover or intend as long as each person was acting individually. For Sartre, this phenomenal awareness of an extended or empowered practical intentionality - from a widened 'origo' as point of reference for that intentionality - underwrites the claim about how the people with whom I act in collective action have become invisible, that is, become indistinguishable from myself ${ }^{1}$.

On account of this description of our example, we can formulate a first explanation for why Sartre would insist on freedom as a feature of collective agency. If this description is plausible, we can suggest that it may be freeing to find the scope and breadth of one's practical intention significantly widened, such that one finds others no longer in one's way, no longer challenging one's action and one's sovereignty. Yet why should we think that others stand in our way in the first place? For example, does it make any sense to think of such others as preventing one from helping the fallen commuter? This glimpse at the reasons behind Sartre's insistence on the role of freedom within collective

the common meanings (significations) which come to him from everywhere either as certainties, by transcending them, or as free choices of means and ends." On this point, cf. ibid., 379-380, 396.

${ }^{1}$ It is for this reason that Sartre will claim that every order and every command in the group seem as much to come from myself, as from anyone else (ibid., 379-380). 
agency can be extended if we look in more detail at the sense of efficacy or agency that a person participating may have as a result of it. We might put this issue in terms akin to those of Tuomela; what does it feel like to go from an Iintention to a we-intention, and from an I-mode-we-intention to a we-mode we-intention? What sort of transition or transformation of a person's agency might be involved in this? This is a further area where Sartre's original contribution to an 'experientially-focused' explanation of collective agency can be seen to come into its own; this transition has to do with the manner in which a new or different sort of agency becomes accessible to individuals, which he frames as a 'liquidation of alterity' and of seriality.

Sartre aims to account for the sort of sociality involved in what he calls the group-in-fusion as arising from another kind of collectivity, namely, seriality, which itself already evinces a kind of "teleology" $(2004,395)$ and a certain 'groupishness', albeit a dissatisfying one. What is seriality about? There are a couple different ways of looking at it. Simplifying a great deal, one way to think about seriality is that it reflects a Sartrean notion of stupidity. In his descriptions of stupidity, Sartre often refers to how stupidity is a reversal of the classical notion of "mens agitat molem" (Sartre 1992, 306), "the idea become matter, or matter aping the idea" (Sartre 1981, 598). In the context of seriality, this notion of stupidity can be understood as the way in which human intentions and actions in the social world become take on the properties and behaviours of inanimate things in the world, like chairs or rocks ${ }^{1}$. In the seriality common to everyday life, however one aims to act and whatever freedom and individuality one may hope to express gets stuck or trapped in a kind of thingness or denseness of one's social being. As just another person waiting in line, i.e. going through the motions and jumping through the hoops of daily life in and with others, one becomes part of "a collective whole that acts like a thing, like a material milieu where the stimuli are propagated mechanically" (Sartre 1968, 207) ${ }^{2}$.

What is important to note here is that such seriality is already a kind of sociality from Sartre's perspective, because it does seem to evince a form of sharing, perhaps not too far removed from what Tuomela denotes as the 'I mode' of the 'we-intention'. However, the sort of sharing involved in seriality

${ }^{1}$ Cf. Sartre 2004, 300, note 88: "And the attraction of racism for intelligent, wellmeaning people (for example, in the form of an innocent pride: 'One has to admit that the Mediterranean races..., etc.') is normally experienced by them as the attraction of stupidity, that is to say, as the secret hope that thought is a stone [la pensée comme un caillou]". Cf. Sartre 1968, 95.

${ }^{2}$ Cf. Sartre 1968, 95. 
is not that of an aggregate and identity of personal goals, but rather one of impotence. As serial beings, we are circulating with other serial beings, moving and interacting in ways governed by modern technology towards the same ends. But as there is a scarcity of places or a scarcity of resources, we all become rivals or obstacles to each other; we are all 'Others'; to each other, challenging and calling into question the sovereignty, that is, the power of agency with which we aim to act and reach our own ends. There is moreover nothing to be done nothing about all these obstacles and the situation of impotence they constitute, because every extra seat on the train, every extra resource created by modern technology, and so on would remain one which have to be potentially competed for with 'Others"1. As Sartre puts it, "powerlessness undergone is the mastic [glue] of seriality" (Sartre 1960, 2272). In seriality, action is quite out of one's own hands; every doing is a non-doing, an "unfreedom" (Flynn $1984,114)$. For this reason, Sartre will speak of the loss of one's own sense of agency and of one's own sense of individuality that occurs through seriality as a type of (self-)alienation $(2004,337)$.

In this respect, seriality is an obstacle to collective agency, and we can also say that for Sartre wherever we see seriality, there can be no collective agency. However, seriality is not just an obstacle, but also a condition for collective agency, qua condition for the emergence of groups that would undertake such agency. That is, in our alienation and the negation of our individuality and freedom in seriality, Sartre would seek the necessary conditions for the emergence of something like a true or authentic form of sociality, the groupin-fusion. One takeaway here is that Sartre's account of the constitution of collective agency goes hand in hand with an account of the dissolution of seriality. The significance of this move should not be lost on us. For Sartre, the problem of collective agency cannot be about how we get from or commute the distance from the individual or personal intention to the collective or shared one ${ }^{3}$. For him, it is rather about how from a certain form of sociality, albeit one in which we are separate but united both at once, we can get to something like a true

\footnotetext{
${ }^{1}$ It is beyond our current scope to examine in depth Sartre's notion of scarcity as an ontological concept. Cf. Sartre 2004, $128 \mathrm{ff}$.

${ }^{2}$ Here we quote and translate the French edition of the Critique of Dialectical Reason. Indeed, there is an error in the English translation: the entire sentence that we cite is omitted.

${ }^{3}$ Sartre's willingness to engage in a reflection on this question, namely the social conditions of collective agency, is an interesting area of his thought that seems to have no direct correlate in accounts such as Tuomela's. It should be noted that Schmid (2009), for one, also purports to avoid this construal of the problem.
} 
sociality, something like a true phenomenon of common action or togetherness. Moreover, this dissolution of seriality, that is to say, such an account of the removal of a kind of impotence, may allow us to see why Sartre holds one of the chief features of collective agency to be the "sudden resurrection of freedom" and an individuation, if not type of self-awareness via participation within collective agency, which is impossible in seriality.

In this connection, with an eye towards the 'experiential dimension' of collective agency, it merits mention that an adequate account of collective agency should also accommodate the affective or emotional dimensions of such agency. That is, an adequate account should allow us to understand what can be rewarding or meaningful about collective agency or 'real' common action. This is what we might suggest some people experience as the 'joy of collective agency'. The idea of collective agency as a recapturing of freedom and of a sense of agency in Sartre can in our view be suggestive for accounting for this joy, as well as allowing to understand why it may be felt, but not always. What might such joy come down to? In the first place, this joy of collective agency seems to have little to do with the throes of a violent passion, such as the overwhelming joy experienced in romantic love, for instance, in those unbearable moments of happiness when it seems like one can no longer stand it, where one must shout one's joy. This is not because the joy of collective agency is necessarily weaker than the former, but because this feeling does not come with a need to be shared or proclaimed by us. Rather the opposite; if this feeling is grounded in a real form of collective agency (and insofar as Sartre tries to make a case for distinguishing as much), there may be little need for it to be shared, because it would involve a togetherness already, namely the event of becoming thirds along with others, through which we shed our seriality. On the other hand, this joy of collective agency is not a matter of selfdetachment or self-serenity, as if it is now the group, and not the self, which has to worry about whether to act, how, and why. Put into the language of the earlier Sartre, this feeling of collective agency cannot be seen as equivalent with a renunciation of individual desire. Instead, this joy may be described as an enjoyment of freedom that has come into its own or that has been instantiated in a novel way through collective agency, and which goes together with a need to sustain one's collective agency in and through the group. In this way, Sartre's descriptions of what it is like to participate in such a group, as this "quasi-subject, quasi-object" (Sartre 2004, 372-373) seem to come very close to what in earlier work he had described as the impossible fulfillment of desire as the 'in-itself-for-itself' or elsewhere as the combination of "subjectivity" and "objectivity" that leads to joy $(1992,498)$. 
In conclusion, it will be worthwhile to consider the extent to which we have responded to the call to which we referred at the beginning of this paper. In one regard, if we have managed to raise a certain question regarding freedom within collective agency, we have certainly not exhausted its possibilities for exploration, not even for the authors we have considered ${ }^{1}$. One item for further examination concerns how to continue to 'translate' the concepts and frameworks advanced by Sartre into the issues at stake in contemporary social ontology, inasmuch as such a process is crucial for any demonstration of the relevance of the former to the latter. Furthermore, it can be worthwhile to reconsider the assumption that Tuomela's views may count as representative of the concerns of social ontology, and thus that they may serve as a touchstone for the questions of collective freedom. Here we might wonder whether other authors would fare differently, insofar as not all contemporary approaches today are homogeneous. This last point then points to a wider conceptual issue to be explored - namely, is our ability to conceptualise this question limited to some greater or lesser extent by the manner in which we pose the 'collectivity' (or sharedness or groupishness) question in the first place? That is, depending on whether we are methodological individualists or not, we may give different sorts of answers to this question. Lastly, it would be interesting to explore whether this question about collective freedom could serve as a motivating factor or "constraint" in Paternotte's sense (2014) for embracing one model or exemplar of collective agency rather than another. In our view, considering the kinds of freedom at stake within collective life, and the sorts that we would want to explain and vouchsafe, could provide a crucial pivot or fulcrum from which to tilt arguments in favour of one set of proposals or another for how to understand how collective agency is constituted and experienced.

Nonetheless, if we have reached some sort of positive result, it would have to be located in how we have looked at whether there could be 'freedom within' collective agency and what it might look like. What we have attempted to understand is how any such freedom creates a kind of tension for social ontologies reliant on mechanisms of commitment and on monitoring how 'others are doing their parts', such as Tuomela's. For him, not all types of collective agency have the same status; some are more collective or more 'groupish'

\footnotetext{
${ }^{1}$ For instance, one further facet of the relation between Tuomela and Sartre concerns the manner in which Sartre describes participants in collective agency as "regulatory thirds" $(2004,379)$. It would be worthwhile to explore whether such a description shows a common interest of both authors in the conditions of enforcing or effecting the common action.
} 
than others, and on his account this has everything to do with the special commitments individuals not only make but also enforce in acting together. This position exposes a basic tension in Tuomela's account between freedom and collective agency. Freedom within collective agency seems only able to exist and be tolerated within collective agency when the latter takes on less coordinated and less cohesive forms. On the other hand, the more the goals or the conditions of collective agency call for greater cooperation and cohesiveness, the more such freedoms form a threat to that very collective agency. This finding presents not only a question as to whether freedom within collective agency is compatible with the "strong we" of Tuomela's proper or "ideal" collective agency; it likewise raises a question about the very nature of the "groupishness' that Tuomela purports to target. Are we a "strong we" when we are most concerned, or when we are least concerned with enforcing each other's commitments as we act together?

This is where our consideration of a Sartrean notion of freedom within collective agency came into play. With Sartre, the question is whether there is a form of freedom which is not only coincident with and dependent upon the institution of collective agency, but that is consonant with it as well (contra Tuomela). If for Tuomela we can only act towards a common goal together insofar as we give up our freedom, for Sartre we can only act towards a common goal together insofar as we have the freedom to, namely, that we are empowered to do so. This last means: insofar as each participant in the common action does not get in the way of any other participant, such that each finds the scope of their practical intentions enlarged by a wider frame of reference for possible ends and goals. Such freedom, we argued, is what Sartre appears to describe as the "common freedom" enjoyed by participants in the group-infusion, where participants experience a freedom unavailable to them outside the common action (i.e. in seriality); that of feeling any one of their own actions could be substituted by actions by any of the other participants. This is, in other words, a freedom from each participants' own sense of impotence in the serial world and a freedom to accomplish more via common action, which at the same time does not cancel or invalidate their participation in the groupin-fusion. A further problem, however, is the transience or instability of 'common action' - and any such freedom going along with it - on Sartre's account. As he readily concedes, any such experience of freedom is quickly threatened by the very conditions of collective agency which give rise to it in the first place ${ }^{1}$. This is where Tuomela may offer an important rejoinder to

${ }^{1}$ Sartre 2004, 420. For an insightful discussion of this issue, cf. De Warren 2016. 
Sartre; if such common freedom is indeed so unstable, is it any kind of noteworthy freedom whatsoever for collective agents?

\section{References}

Arnstein, S. 1969. "A Ladder of Citizen Participation". Journal of the American Institute of Planners, 35(4) (1969), 216--224.

Butterfill. S. 2015. "Planning for Collective Agency" in Misselhorn, C. [ed]. Collective Agency and Cooperation in Natural and Artificial Systems: Explanation, Implementation, and Simulation. Cham: Springer, 149-168.

Caws, P. 2005. "The Distributive Structure of the Social Group". Journal of Social Philosophy, 36(2) (2005), 218-232.

Cohen, G. A. 1991. "Capitalism, Freedom and the Proletariat" in Miller, D. [ed]. Liberty. Oxford: Oxford University Press.

De Warren, N. 2016. "Brothers in Arms: Fraternity-Terror in Sartre's Social Ontology" in Moran, D. \& Szanto, T. [eds]. Phenomenology of Sociality: Discovering the "We". New York: Routledge, 313-326.

Flynn, T. 1984. Sartre and Marxist Existentialism: The Test Case of Collective Responsibility. Chicago: University of Chicago Press.

Gilbert, M. 2009. "Shared Intention and Personal Intentions". Philosophical Studies, $144,167-187$.

Goffman, E. 1956. The Presentation of Self in Everyday Life. Edinburgh: University of Edinburgh.

Goffman, E. 1971. Relations in Public: Microstudies of the Public Order. New York: Basic Books.

Gomez-Lavin, J. \& Rachar, M. "Normativity in Joint Action". Mind and Language, 34 (2019), 97-120.

Hindriks, F. 2008. "The Freedom of Collective Agents". Journal of Political Philosophy, 16(2), 165-183.

Kramer, M. H. 2003. The Quality of Freedom. Oxford: Oxford University Press.

León, F \& Zahavi, D. 2016. "Phenomenology of Experiential Sharing: The Contribution of Schutz \& Walther" in Salice, A. \& Schmid, H.-B. [eds]. Social Reality: The Phenomenological Approach. Cham: Springer, 219-234.

Paternotte, C. 2014. "Constraints on Joint Action" in Gallotti, M. \& Michael, J. [eds]. Perspectives on Social Ontology and Social Cognition. Dordrecht: Springer, 103124.

Pettit, P. 2001. A Theory of Freedom. Cambridge: Polity Press.

Ritchie, K. 2015. "The Metaphysics of Social Groups". Philosophy Compass, 10/5, $310-321$.

Sartre, J-P. 1960. Critique de la Raison dialectique. Paris: Gallimard.

Sartre, J-.P. 1968. The Communists and Peace. Fletcher, M. trans. New York: George Braziller. 
Sartre, J-.P. 1981. The Family Idiot: Volume I. Cosman, C., trans. Chicago: University of Chicago Press.

Sartre, J-.P. 1992. Notebooks for an Ethics. Pellauer, D., trans. Chicago: University of Chicago Press.

Sartre, J-.P. 2004. Critique of Dialectical Reason. Volume I. Sheridan-Smith, A. trans. London: Verso.

Schmid, H. B. 2009. Plural Action. Dordrecht: Springer.

Schweikard, D. 2017. "Voluntary Groups, Noncompliance, and Conflicts of Reason: Tuomela on Acting as a Group-Member" in Preyer, G. \& Meyer, G. [eds]. Social Ontology and Collective Intentionality: Critical Essays on the Philosophy of Raimo Tuomela with His Responses. Cham: Springer, 97-112.

Tollefsen, D. 2014. "A Dynamic Theory of Shared Intention and the Phenomenology of Joint Action" in Chant, R., Hindriks, F. \& Preyer, G. [eds]. From Individual to Collective Intentionality: New Essays. New York: Oxford University Press, 13-33.

Tuomela, R. 2007. The Philosophy of Sociality: The Shared Point of View. Oxford: Oxford University.

Tuomela, R. 2013. Social Ontology. Oxford: Oxford University Press.

Zahavi, D. 2014. "Empathy and Other-Directed Intentionality”. Topoi, 33, 129-142. 